\title{
Regularización dominial de inmuebles rurales para agricultores familiares
}

\author{
Domain regularization of rural properties \\ for family farmers
}

Regularização de domínios de propriedades rurais para agricultores familiares

"Régularisation du domaine des propriétés rurales pour des agriculteurs fami-liaux"

家庭农民的农村财产领域正规化

\author{
Lorena Muñoz ${ }^{1}$ y Natalia L. Barriviera ${ }^{2}$ \\ Universidad Nacional de La Plata - Argentina
}

Revista Derechos en Acción ISSN 2525-1678/ e-ISSN 2525-1686

Año 5/Nº 15, Otoño 2020 (21 marzo a 20 junio), 85-104

DOI: https://doi.org/10.24215/25251678e390

Recibido: 01/12/2019

Aprobado: 01/02/2020

Resumen: El presente artículo analiza la modificación efectuada por la Ley $N^{0} 27.118$ a la Ley $N^{0} 24.374$ (conocida como Ley Pierri, cuyo objeto es la regularización dominial de inmuebles urbanos), alcanzando con su entrada en vigencia a los agricultores familiares poseedores de inmuebles rurales donde residan y produzcan, como beneficiarios

\footnotetext{
1 Lorena Muñoz. Abogada-Escribana (UNLP). Profesora Adjunta Ordinaria en la materia Derecho Notarial y Registral. (Fac. Cs. Jcas. y Soc- UNLP). Subdirectora Especialización en Documentación y Registración Inmobiliaria (Fac. Cs. Jcas. y Soc- UNLP). Docente Investigador Categoría V. (ORCID 0000-0003-2142-4710) Correo electrónico: lore_2011@hotmail.com.

2 Natalia Lorena Barriviera. Abogada-Escribana (UNLP). Profesora Adjunta Ordinaria en Derecho Notarial y Registral (Fac. Cs. Jcas. y Soc- UNLP). Secretaria Instituto de Investigación en Derecho Notarial y Registral (Fac. Cs. Jcas. y Soc- UNLP). (ORCID 0000-0002-5941-6807). Correo electrónico: nataliabarriviera@gmail.com.
} 
de la ley, concediéndoles de tal modo la posibilidad de acogerse a los beneficios de esta ley de regularización dominial para obtener su título de propiedad. Asimismo, se reflexiona sobre la ausencia a la fecha, de reglamentación en la provincia de Buenos Aires de la Ley № 27.118, y se enumeran algunos aspectos a tener en cuenta, fundamentalmente con la finalidad de poder incluir como beneficiarios de la regularización a los agricultores familiares que habitan y producen en la zona denominada "cordón flori-frutihortícola de La Plata", considerado uno de los sectores de mayor producción de frutas y verduras del país.

Palabras clave: Inmuebles rurales, regularización, derecho registral.

Abstract: This article analyzes the modification made by Law No. 27.118 to Law No. 24.374 (known as the Pierri Law, whose object is the regularization of urban properties), which applies to family farmers who own rural properties where they reside and produce, as beneficiaries, granting them the possibility of receiving the benefits of this law to obtain their property title. Likewise, it reflects on the absence of regulations in the province of Buenos Aires of Law No. 27,118, and lists some aspects to consider, in order to include comme beneficiaries those family farmers who live and produce in the area called "flori-fruit and vegetable cord of La Plata", considered one of the sectors with the highest production of fruits and vegetables in the country.

Keywords: Rural properties, regularization, registry law

Resumo: 0 presente artigo analisa a modificação efetuada pela Lei $n^{0} 27.118$ à Lei $n^{0} 24.374$ (conhecida como Lei de Pierri, cujo objetivo é a regularização de domínio de propriedades urbanas), alcançando com a sua entrada em vigor aos agricultores familiares titulares de propriedades rurais onde residem e produzem, como beneficiários da lei, concedendo-lhes a possibilidade de qualificar aos benefícios dessa lei de regularização de domínio para obter seu título de propriedade. Da mesma forma, pondera-se sobre a au-sência, até o momento, de regulamentos na província de Buenos Aires da Lei $n^{0} 27.118$, e são listados alguns aspectos a ter em consideração, principalmente com a finalidades de poder incluir como beneficiários da regularização aos agricultores familiares que vivem e produzem na área denominada "cordão flori-frutihortícola de La Plata", considerado um dos setores de maior produção de frutas e vegetais do país 
Palavras-chave: Propriedades rurais, regularização, direito de registro.

Résumé: Cet article analyse la modification apportée par la loi nº 27.118 à la loi n 24.374 (connue comme loi Pierri, dont l'objet est la régularisation des biens immobiliers urbains), qui s'applique aux agriculteurs familiaux propriétaires de biens immobiliers rural où ils résident et produisent, en leur donnant la possibilité de bénéficier des avantages de cette loi pour obtenir leur titre de propriété. Également, il réfléchit à l'absence de réglementation dans la province de Buenos Aires de la loi $n^{0} 27.118$, et énumère certains aspects à prendre en compte, principalement dans le but de pouvoir inclure comme bénéficiaires aux agriculteurs familiaux qui habitent et produisent dans la zone appelée "La Plata flori-frutihortícola cord", qui est considérée comme l'un des secteurs ayant la plus forte production de fruits et légumes du pays.

Mot-clés: Propriétés rurales, régularisation, droit d'enregistrement

摘要: 本文分析了第27,118号法律对第24,374号法律 (被称为" Pierri 法", 其目标是城市财产的正规化) 所作的修改, 从而使拥有农村财 产的家庭农民生效。他们作为法律的受益人居住和生产的地方, 从 而使他们有可能利用该领域正则化法律的利益来获得其财产权。同 样, 它反映了布宜诺斯艾利斯省第27118号法律的法规迄今尚不存 在, 并列出了一些要考虑的方面, 主要是为了能够包括对这些法规 进行正规化的受益者。在"拉普拉塔的花果蔬封锁带"地区生活和生 产的家庭农民, 被认为是该国果蔬产量最高的部门之一

关键词: 农村财产, 正规化, 登记法.

\section{Introducción}

Concluyendo el año 2014, en el marco de consenso de todos los actores de la agricultura familiar, tanto los campesinos, los pueblos originarios, las organizaciones y el Estado, se sanciona la Ley 27.118 titulada "Reparación histórica de la agricultura familiar para la construcción de una nueva ruralidad en la argentina", que parte de la premisa de declarar, en su artículo primero, de interés público la agricultura familiar, campesina e indígena por su contribución a la seguridad y soberanía 
alimentaria del pueblo, por practicar y promover sistemas de vida y de producción que preservan la biodiversidad y procesos sostenibles de transformación productiva. ${ }^{3}$

En los fundamentos de la citada norma, conocida como ley de reparación histórica para la Agricultura Familiar, se señala entre sus objetivos, el desarrollo humano integral de los agentes rurales a través del impulso del empleo en armonía con el territorio, también el promover la igualdad y corregir disparidades de desarrollo regional, contribuir a la soberanía y seguridad alimentaria, fomentar la conservación de la biodiversidad y el mejoramiento de la calidad de los recursos naturales mediante un aprovechamiento sustentable, reconocer las prácticas de vida y productivas de los pueblos originarios, y la regulación dominial mediante un programa específico y permanente para el relevamiento de las tierras de la agricultura familiar y la conformación de una Comisión Nacional Permanente de regulación dominial.

Este último punto es el que adquiere especial relevancia en el presente trabajo, ya que el objetivo es analizar uno de los mecanismos mediante los cuales los beneficiarios de esta norma -agricultores familiares- podrían acceder a la titulación formal de su tierra y destacar los beneficios que ello trae aparejado, especialmente en el ámbito rural.

La problemática de la ausencia de titulación formal o deficiencia en la misma, no es un tema menor, en ningún tipo de inmuebles, sean urbanos o rurales. No obstante, cabe tener presente que en el caso de los inmuebles rurales, donde dicho suelo además de ser sustrato para la vivienda es la fuente de recursos para quienes lo habitan, adquiere especial significancia para los poseedores del mismo.

Precisamente, en los fundamentos de la norma bajo análisis, se ponen de relieve los reclamos de seguridad jurídica en la tenencia de la tierra, generada desde organizaciones de base

3 La Ley 27.118 fue sancionada el 17 de Diciembre de 2014 y promulgada de Hecho el 20 de Enero de 2015. 
(campesinas e indígenas) y de aquellas organizaciones de la sociedad civil que acompañan estos procesos, debido a la existencia de innumerables situaciones de ocupación y posesión de bienes inmuebles o tierras transmitidas de generación en generación por parte de los sujetos de la agricultura familiar, campesina e indígena, sin titularidad de dominio o bajo una condición jurídica formalizada en forma parcial, y la amenaza constante de desalojos a dichos habitantes.

En esta dirección, una de las pautas de la ley en comentario ha sido la de suspender "... por tres (3) años toda ejecución de sentencia y actos procesales o de becho que tengan por objeto el desalojo de agricultores familiares que al momento de la entrada en vigencia de la presente norma se encuentren en condiciones de usucapir las tierras rurales que poseen", agregando que "La autoridad de aplicación de conformidad a los artículos precedentes, priorizará soluciones inmediatas para garantizar la permanencia y el acceso a la tierra"

El propósito de dicha disposición es la de evitar la pérdida de la posesión real o el desapoderamiento de las tierras, garantizándoles a los pequeños productores la tranquilidad que no serán desalojados y podrán llevar adelante el proceso de regularización de estos inmuebles en el marco de los beneficios que propone la ley de agricultura familiar.

Así, en pos de concretar la seguridad jurídica sobre la posesión de estas tierras, la Ley 27.118 introduce una importante herramienta para el saneamiento en la titulación de inmuebles rurales destinados a la producción agrícola habitados por familias que trabajen dichos suelos.

La herramienta a la que referimos, es la posibilidad otorgada a estos poseedores de tierras rurales para que puedan ser beneficiarios de la llamada "Ley Pierri", norma que ha

4 Art. 19 de la Ley 27.118. Por art. 124 de la Ley N 27.431 B.0. 2/1/2018 se prorroga hasta el 31 de diciembre de 2018 la vigencia de la suspensión dispuesta en el presente artículo.

5 Ello por cuanto el diputado nacional Pierri, fue uno de los autores y propulsor del proyecto. 
llevado adelante uno de los planes de regularización dominial más exitosos, desde el punto de vista del mecanismo que ha instaurado y por la masividad en términos de beneficiarios que han obtenido su título de propiedad a través del mismo.

Este mecanismo de regularización dominial, hasta la sanción de la Ley 27.118 , disponía en el art. $1^{\circ}$ de la Ley 24.374 , con sus modificaciones por las leyes 25.797 y 26.493 que "Gozarán de los beneficios de esta ley los ocupantes que, con causa lícita, acrediten la posesión pública, pacífica y continua durante tres (3) años con anterioridad al $1^{\circ}$ de enero de 2009, respecto de inmuebles edificados urbanos que tengan como destino principal el de casa babitación única y permanente, y reúnan las características previstas en la reglamentación."

De tal modo adviértase que, hasta el año $2015^{6}$ los posibles beneficiarios de la regularización dominial eran sólo poseedores de inmuebles urbanos, resultando de suma relevancia el agregado que introduce el art. 35 de la Ley $27.118 \mathrm{al}$ art. $1^{\circ}$ de la ley 24.374 , beneficiando ahora a los agricultores familiares poseedores de inmuebles rurales que habiten y hagan producir esas tierras. El párrafo agregado dice:

"En las mismas condiciones podrán acceder a estos beneficios los agricultores familiares respecto del inmueble rural donde residan y produzcan."

\section{Consecuencias que trae aparejada la ausencia o falta de titulación, especialmente para los agricultores familiares}

Tal como se mencionara en los fundamentos de la Ley 27.118, las comunidades campesinas e indígenas, padecen las consecuencias de la ausencia o deficiencia en la titulación, a través de la inseguridad que ello les genera en la tenencia de sus tierras. Inevitablemente, ello conduce en muchos casos a una disminución en la productividad de las tierras por la necesidad

6 Recordemos que la Ley 27.118 entró en vigencia el 20 de enero de 2015. 
de destinar mano de obra activa a cuidar la tenencia; o el desinterés por trabajar la tierra ante posibles desalojos; la migración desde el sector rural hacia las ciudades debido a la carencia de seguridad en la tenencia de la tierra, la imposibilidad de acceder a cierto tipo de créditos o prestamos para mejorar la vivienda o producir la tierra, debido a la imposibilidad de acreditar la titularidad de los inmuebles dados en garantía, sólo por mencionar algunos inconvenientes.

Y numerosos son también los obstáculos que encuentran los poseedores de estas tierras para obtener el título formal de sus inmuebles. Entre ellos cabe citar, los costos de juicio de usucapión, los costos de los trabajos de mensura de las tierras, la ausencia o carencia de asesoramiento jurídico, y consecuentemente el desconocimiento de los derechos de los poseedores; obstáculos en el acceso a la justicia; los costos de traslado a los centros urbanos para realizar trámites judiciales o administrativos, entre muchos otros.

En efecto, si bien las problemáticas vinculadas a la tenencia de la tierra no se reducen exclusivamente a la falta de títulos de propiedad, esta carencia origina situaciones básicas de inestabilidad por potenciales desalojos, además de acotar la posibilidad de acceder a créditos para incorporar capital, dificultando enormemente la consolidación productiva de los pequeños establecimientos familiares. $^{7}$

\section{Beneficiarios de la Regularización dominial de tierras rurales conforme Ley 27.118}

Cabe ahora detenerse en el universo de beneficiarios que podrían acogerse a la regularización dominial de tierras rurales.

7 Slutzky, Daniel (2008): "Situaciones problemáticas de tenencia de la tierra en Argentina". Ministerio de Economía y Producción - Secretaría de Agricultura, Ganadería, Pesca y Alimentos - Dirección de Desarrollo Agropecuario - PROINDER - Serie Estudios e Investigaciones $N^{0}$ 14. Disponible en redaf.org.ar/wp-content/uploads/2008/08/problematicas-de-tenenciadela-tierra.pdf. Citado en GAPEL REDCOZUB, Guillermo. Políticas de regularización dominial de tierras rurales: el plan de la provincia de Corrientes, Argentina. Revista de la Facultad de 
Recordemos que el agregado que introduce la Ley 27.118 a la Ley Pierri refiere a "agricultores familiares respecto del inmueble rural donde residan y produzcan."

En primer lugar delimitemos el concepto de agricultores familiares. En los términos de la ley bajo análisis (art. 5 Ley 27.118):

"Se define como agricultor y agricultora familiar a aquel que lleva adelante actividades productivas agrícolas, pecuarias, forestal, pesquera y acuícola en el medio rural y reúne los siguientes requisitos:

a) La gestión del emprendimiento productivo es ejercida directamente por el productor y/o algún miembro de su familia;

b) Es propietario de la totalidad o de parte de los medios de producción;

c) Los requerimientos del trabajo son cubiertos principalmente por la mano de obra familiar y/o con aportes complementarios de asalariados;

d) La familia del agricultor y agricultora reside en el campo o en la localidad más próxima a él;

e) Tener como ingreso económico principal de su familia la actividad agropecuaria de su establecimiento;

f) Los pequeños productores, minifundistas, campesinos, chacareros, colonos, medieros, pescadores artesanales, productor familiar y, también los campesinos y productores rurales sin tierra, los productores periurbanos y las comunidades de pueblos originarios comprendidos en los incisos a), b), c), d) y e)."

Sumado a los recaudos que permitirían calificar quién entra en la categoría de agricultor familiar, el art. 6 de la Ley 27.118 exige la obligación de registrarse en forma individual y asociativa, a los efectos de ser incluidos en los beneficios de la ley, dando lugar al Registro Nacional de Agricultura Familiar (RENAF). 
De tal modo, entendemos que será el $\operatorname{RENAF}^{8}$ quién deberá evaluar y calificar los recaudos para ser considerado agricultor familiar, debiendo entonces solamente acreditar estar registrado allí para gozar los beneficios de la regularización dominial.

De otra parte, aunque resulte sobreabundante señalarlo, el inmueble objeto de regularización dominial debe ubicarse en una zona categorizada como rural. Aquí cabría preguntarnos que pasa con los inmuebles que se encuentran en zonas periurbanas o semi rurales destinados a agricultura familiar y se cumplen a su respecto los restantes recaudos. ${ }^{9}$ Entendemos que una adecuada reglamentación de dicha norma en el ámbito local deberá prever y regular estas situaciones, permitiendo encuadrarlas dentro de los beneficios de la regularización dominial rural teniendo en cuenta la finalidad de dichos inmuebles más allá de su zonificación como rural o urbana, como también deberá especificar ciertas características que deberán reunir dichos inmuebles para ser acogidos en la regularización, como superficie máxima del inmueble, superficie cultivada, particularidades de las edificaciones, entre otras cuestiones.

A su vez, conforme los términos de la ley, el inmueble debe tener una vivienda, es decir debe haber una edificación, en la cual residan los agricultores que se acogen a los beneficios de la ley.

$\mathrm{Al}$ respecto es preciso detenernos en las características particulares de los inmuebles destinados a la agricultura familiar,

8 El Registro Nacional de Agricultura Familiar se encuentra bajo la órbita del Ministerio de Agricultura, Ganadería y Pesca de la Nación, y en su sitio web señala que Con su inscripción en el ReNAF, los Agricultores y Agricultoras Familiares obtienen una certificación oficial de su actividad que les permite acceder de forma prioritaria a programas y proyectos para el sector y a los derechos consagrados en la Ley de Reparación Histórica de la Agricultura Familiar 27.118.

https://www.agroindustria.gob.ar/sitio/areas/d_registros_y_monotributo_agropecuario/renaf/index.php

9 Al respecto, existen alrededor de las ciudades de La Plata y Mar del Plata un cordón frutihortícola que abarca una amplia región en superficie, con una importante producción para la Provincia de Buenos Aires, donde su zonificación no es estrictamente rural, pero sus productores encuadrarían en las previsiones de la Ley 27.118. 
donde debemos dejar de lado una noción estática del fundo, propia de los inmuebles urbanos y una mirada estrictamente desde el derecho civil, para hacer lugar a una noción dinámica de estos inmuebles rurales destinados a la producción agroeconómica, con sus particularidades propias y propiciar una mirada amplia involucrando otras ramas del derecho como el ambiental, el agrario, etc.

\section{Procedimiento de la Ley 24.374 de Regularización dominial}

Luego de haber delimitado el universo de beneficiarios que incorpora la Ley 27.118 al procedimiento de regularización dominial, resulta oportuno referirnos al mecanismo a través del cual pueden obtener el título formal de su vivienda, en el ámbito de la Provincia de Buenos Aires, ya que si bien estamos frente a una ley nacional, ésta ha facultado a las provincias -y a la entonces municipalidad de la Ciudad de Buenos Aires-, a determinar en sus respectivas jurisdicciones la autoridad de aplicación de dicho régimen, como así también a dictar las normas reglamentarias y procedimientos necesarios para su operatividad. ${ }^{10}$

Cabe señalar que la Ley 27.118 no ha sido reglamentada todavía, ni a nivel nacional, ni en su correlato provincial, y menos aun en los aspectos específicos sobre regularización dominial. Ello deviene imperiosamente necesario, a fin de que los posibles agricultores familiares que reúnan los requisitos establecidos por la norma puedan acogerse a la ley, conforme se encuentra estructurado el plan de regularización, y que el mecanismo actualmente previsto sea ajustado a este nuevo supuesto.

El procedimiento, tal como se encuentra previsto en el ámbito local actualmente, presenta dos etapas diferenciadas en cuanto a

10 En tal sentido la Provincia de Buenos Aires dictó el Decreto N 3991/94 (modif. por Decreto N²815/96), reglamentario de la Ley 24.374, y el Decreto Provincial N²26/95 que aprueba el Convenio celebrado entre el Colegio de Escribanos local y el Gobierno Provincial. 
su procedimiento y finalidad, la de acogimiento y la de consolidación, las cuales aun se encuentran separadas temporalmente.

En la primera instancia que podemos denominar, "etapa de acogimiento", en el ámbito de la Provincia de Buenos Aires, se realiza ante los Registros Notariales de Regularización Dominial (RNRD). ${ }^{11}$ Los interesados se presentan ante el escribano regularizador con la documentación por la cual acreditan los requisitos para ser beneficiario. ${ }^{12}$

Conforme lo previsto por el art. $6^{\circ}$ inc. a) de la Ley 24.374 , los beneficiarios deberán presentar "una solicitud de acogimiento al presente régimen, con sus datos personales, las características y ubicación del inmueble, especificando las medidas, linderos y superficies, datos dominiales y catastrales si los tuviese, y toda documentación o título que obrase en su poder...” y "acompañar una declaración jurada en la que conste su carácter de poseedor del inmueble, origen de la posesión, año de la que data la misma, y todo otro requisito que prevea la reglamentación". ${ }^{13}$

11 En un principio se crearon las llamadas "Casas de Tierras" en los distintos municipios, encargadas de difundir y promocionar la ley, realizando las verificaciones y relevamientos correspondientes, mientras que la Escribanía General de Gobierno se ocupaba del otorgamiento de las respectivas escrituras (conf. art. $6^{\circ}, 7^{\circ}$ y $9^{\circ}$ Decreto $N^{\circ} 3991 / 94$ ). Posteriormente, a consecuencia de una pobre acogida a la norma, el gobierno de Duhalde suscribe un convenio con el Colegio de Escribanos con fecha 6/2/1995 (aprobado por Decreto № 226/95) por medio del cual se encomendaba a ciertos notarios las tareas precitadas, previendo la conformación de Registros Notariales de Regularización Dominial (RNRD), los que fueron creados por Decreto N $N^{0} 3152 / 96$. De este modo, la verificación de los extremos requeridos por la ley, y el otorgamiento de la escritura respectiva queda a cargo de los Notarios "Encargados" de las Casas de Tierras y de sus "Colaboradores", todos ellos notarios de la matrícula que accedieron mediante un procedimiento de selección y formación previo, a cargo del Colegio de Escribanos en conjunto con la autoridad de aplicación. Luego complementada por normativa de la autoridad de aplicación: Disposición 91/03 Designación de Notarios colaboradores, Resolución 64/2007 y Designación de Notarios integrantes de un R.N.R.D.

12 Actualmente existe un Instructivo de procedimiento: Resolución N 33/2012 de la Subsecretaria Social de Tierras, Urbanismo y Vivienda.

13 Al respecto los arts. $3^{\circ}$ y $4^{\circ}$ del Decreto local 3991/94, determinan ciertas características que deberán reunir los inmuebles en cuestión. Ahora bien, en este caso, deberán calificar que se trata de un inmueble rural, donde hay una vivienda que habita el agricultor familiar y que éste se encuentra inscripto en el Registro Nacional de Agricultura Familiar. 
Cabe detallar, como documentación que pueda aportar el beneficiario y le permita acreditar la antigüedad y continuidad de la ocupación en el inmueble con anterioridad al año 2006, los siguientes: boleto de compraventa, cesión de derechos, libreta de pagos, títulos antecedentes, recibo de compra del lote, cesión de derechos posesorios documentos de identidad con el domicilio allí radicado, recibos de pagos de tasas municipales e impuestos provinciales, recibos de pagos de servicios del domicilio, planos del inmueble, boletines escolares, facturas de compra de materiales o insumos para el inmueble, certificados de trabajo, siempre que en ellos conste el domicilio del bien a regularizar.

El escribano interviniente solicita un informe de dominio, cédula y plancheta catastral, respecto del inmueble objeto de regularización. Realiza asimismo un relevamiento social (a fin de verificar la efectiva ocupación del inmueble por el beneficiario y su grupo familiar) y técnico (a fin de verificar las características y condiciones del inmueble). Luego procede a citar al titular registral del inmueble, notificándolo al último domicilio conocido, y emplaza, mediante publicación de edicto, a toda persona que se considere con derechos sobre el inmueble, para que deduzcan oposición en el término de 30 días. ${ }^{14}$

Con toda la documentación recolectada, el notario forma un expediente, y da intervención a la autoridad de aplicación para verificar lo obrado en las actuaciones administrativas ${ }^{15}$. Cumplido ello, aprobado el trámite, el notario autoriza la escritura pública a que se refiere el artículo $6^{\circ}$ inc. e) de la ley, la cual

\footnotetext{
14 Art. $6^{\circ}$ inc. d) de la Ley 24.374. En el supuesto que concurra el titular de dominio, y preste su consentimiento para realizar la transmisión en favor del beneficiario, la instrumentación pertinente, si bien gozará de los beneficios y exenciones previstos por la ley, se sujetará a las normas de derecho común, con lo cual, en este caso nos encontramos frente a una verdadera escritura traslativa del dominio, conf. art. $6^{\circ}$ inc. h) de la Ley 24.374. En este supuesto se produce la transmisión y consecuente adquisición del dominio pleno en forma inmediata en cabeza del beneficiario.

15 La autoridad de aplicación actual conforme Decreto 40/2015, es la Subsecretaría Social de Tierras, Urbanismo y Vivienda, complementado por Decreto 360/2016. El control se limita a verificar el cumplimiento de los requisitos y del procedimiento previstos en la Ley $N^{0} 24.374$.
} 
es suscripta por el beneficiario y el representante de la autoridad de aplicación. En rigor de verdad, tal instrumento es un acta de protocolización, denominada "acta-Ley 24.374", que contiene una relación de las actuaciones administrativas. ${ }^{16}$

Dicha escritura se inscribe en el Registro de la Propiedad Inmueble correspondiente, a fin de computar el inicio del plazo de diez años que establece actualmente el artículo 8 de la Ley 24.374, para obtener el dominio perfecto transcurrido dicho plazo.

Cabe resaltar, que el presente régimen estableció la gratuidad de los trámites que se realicen en el marco del mismo. ${ }^{17}$

Transcurridos diez años contados a partir de su registración, la inscripción registral se convertirá de pleno derecho en dominio perfecto. ${ }^{18}$

Sin perjuicio que, de los términos de la normativa, parecería indicar que la consolidación opera de manera automática, la

16 Muñoz, Lorena, Regularización dominial: A más de una década de la ley 24.374. Estado de la consolidación de dominio en la Provincia de Buenos Aires y una posible actualización del régimen, La Ley Online; UNLP 2008-38, 409.

17 El beneficiario sólo tendrá que abonar una contribución especial del $1 \%$ del valor fiscal del inmueble (conf. arts. $3^{\circ}$ y $9^{\circ}$ Ley 24.374). Por su parte el art. 20 del Decreto Provincial $N^{0} 3991 / 94$ creo una cuenta especial, conformada por estos aportes, denominada "Fondo de Financiamiento para el Régimen de Titularización de Inmuebles Ley 24.374", la cual será administrada por la autoridad de aplicación. A su vez, el art. $3^{\circ}$ de la Ley 24.374 estableció que, la existencia de deudas tributarias, impositivas o de tasas que recaigan sobre el inmueble, ya fueran de jurisdicción nacional, provincial o municipal, no constituyen impedimentos para acogerse a este régimen.

18 Art. $8^{\circ}$ de la Ley 24.374 conforme redacción dada por la Ley 25.797 del año 2003. Textualmente la norma dispone: "La inscripción registral a que se refiere el inciso e del Art. $6^{\circ}$ se convertirá de pleno derecho en dominio perfecto transcurrido el plazo de diez años contados a partir de su registración. Los titulares de dominio y/o quienes se consideren con derecho sobre los inmuebles que resulten objeto de dicha inscripción podrán ejercer las acciones que correspondan inclusive, en su caso, la de expropiación inversa, hasta que se cumpla el plazo aludido. Las provincias dictarán las normas reglamentarias y disposiciones catastrales y registrales pertinentes para la obtención de la escritura de dominio o título". En el ámbito de la Provincia de Buenos Aires fue reglamentado por el Decreto 181/2006. Sumado a ello se ha dictado un Instructivo de procedimiento aprobado por Resolución 32/2012 de la Subsecretaría Social de Tierras, Urbanismo y Vivienda, y la Dirección Provincial del Registro de la Propiedad Inmueble de la Provincia de Bs.As. ha dictado la Disposición Técnico Registral N²/2011. 
misma no funciona en forma instantánea, sino que requiere un trámite integrado por distintos pasos.

Así en esta segunda instancia, que podemos denominar "etapa de consolidación", los interesados deberán dirigirse al Registro Notarial de Regularización Dominial (RNRD) correspondiente, y presentar allí la solicitud de consolidación, la cual tendrá carácter de declaración jurada, junto con la documentación pertinente que avale su beneficio.

Los sujetos facultados a instar el procedimiento de consolidación pueden ser, los beneficiarios de las actas-ley 24.374; los cesionarios por actos entre vivos o a título universal; los herederos; y los terceros involucrados. ${ }^{19}$

El notario interviniente deberá peticionar un informe de dominio del inmueble en cuestión, a fin de constatar la correcta inscripción del derecho del beneficiario y la situación jurídica del bien, como así también debe solicitar la cédula y plancheta catastral, a efectos de verificar su situación física e individualizar correctamente el inmueble a consolidar.

Con la documentación e informes solicitados, el notario forma un nuevo expediente administrativo, y lo remite a la autoridad de aplicación, para que realice el visado de dichas actuaciones, control que se limita a la legalidad de las formas extrínsecas de las actuaciones y al cumplimiento del procedimiento previsto en la normativa.

Visado el expediente, es devuelto al notario interviniente, quien redacta el acta de consolidación, la cual es suscripta por el funcionario a cargo de la autoridad de aplicación, y luego llevada al Registro de la Propiedad Inmueble para su registración.

El mecanismo que muy sucintamente hemos descripto, culmina con la entrega al poseedor del inmueble del título formal de su propiedad.

19 Art. 2 Decreto 181/2006. 


\section{Inexistencia de disposiciones específicas en materia de inmuebles rurales. Necesidad de una reglamentación especial en el ámbito provincial}

El procedimiento señalado al que brevemente hemos referenciado, concede a los ocupantes de dichos inmuebles un título de propiedad sobre los mismos convirtiéndolos en titulares dominiales, y permite la incorporación del inmueble al mercado formal de tierras al sanear las deficiencias de que padecía en cuanto a su titulación.

A más de haber referenciado la reglamentación existente en la Provincia de Buenos Aires sobre el procedimiento de regularización dominial en el marco de la Ley 24.374 y sus modificatorias, no se advierte mención ni regulación específica alguna en torno al supuesto de regularización dominial de inmuebles rurales para agricultores familiares conforme el agregado que ha efectuado la Ley 27.118.

Si bien la posibilidad de someter a regularización dominial inmuebles rurales ya se encuentra consagrada en la norma nacional, la circunstancia de que la misma aun no se encuentre reglamentada en la Provincia de Buenos Aires dificulta la operatividad de esta opción en el ámbito local ya que el art. $5^{\circ}$ de la Ley 24.374 determina que "Las provincias ... dictarán las normas reglamentarias y procedimientos para su cumplimiento, teniendo en cuenta las normas de planeamiento urbano y procediendo en su caso, a un reordenamiento adecuado". De tal modo, esta ausencia de reglamentación representa un obstáculo al momento de pretender aplicar esta opción en el ámbito local por las circunstancias particulares que evidencian estos supuestos de regularización dominial de inmuebles rurales para agricultores familiares.

De tal modo, consideramos imperiosa la necesidad de contar con una reglamentación para este supuesto especial de inmuebles objeto de regularización dominial, la que debería tener mínimamente en cuenta estos aspectos: 
- Características relativas al inmueble a regularizar: zonificación, superficie, tipo de edificación, entre otros.

- Recaudos vinculados a los beneficiarios de la regularización: inscripción en el RENAF, o el modo de acreditar que se trata de agricultores familiares que residen y producen en dichas tierras.

- Especiales consideraciones en torno a la documentación que acredite la ocupación en dichas tierras, especialmente en el caso de comunidades indígenas.

- Especiales consideraciones para realizar las constataciones in situ de dichos inmuebles

Solo por mencionar algunas condiciones fundamentales que la reglamentación local debería determinar a fin de hacer operativa este tipo de regularización dominial.

\section{Posible aplicación de esta norma para el cordón flori-frutihortícola de La Plata}

Existe una importante región dentro del Partido de La Plata, en cuanto a su extensión territorial y su significación en términos económicos-productivos, el llamado cordón flori-frutihortícola de La Plata, en la cual habitan miles de familias que trabajan y producen dichas tierras, abasteciendo con su producción el consumo de frutas y verduras de más de 12 millones de argentinos. $^{20}$

Es considerada una de las zonas de mayor producción flori-frutihortícola del país. Al respecto se ha señalado que en América Latina y el Caribe, la Agricultura Familiar representa el 80 \% del total de los desarrollos agrícolas existentes y, sólo el Cordón Verde de las localidades de Berazategui, Florencio Varela y La Plata, representa más de 30.000 puestos de trabajo y abastece aproximadamente el $70 \%$ de los alimentos frescos del

20 Ver publicación Diario El Día de fecha 24/11/2020 https://www.eldia.com/nota/201911-24-2-15-54-la-precariedad-en-la-gran-quinta-del-pais-las-dos-caras-del-cordon-horticola-platense-la-ciudad. 
Área Metropolitana de Buenos Aires, destacando la importancia estratégica de este sector en el desarrollo socio-económico nacional y provincial. ${ }^{21}$

Si bien los productores familiares que habitan en dicha zona, en su mayoría son arrendatarios ${ }^{22}$, posiblemente en otros tantos supuestos se encuentren ante una posesión informal de los inmuebles, cumpliendo todos los recaudos para ser considerados dueños de ellos, pero sin contar el con el título de su propiedad, con el impacto negativo que ello acarrea, como se ha puesto de relieve, en especial en el caso de estos inmuebles donde las familias no solo viven allí sino que además la tierra es su fuente de ingresos.

En estos casos entendemos que sería factible y plausible que los productores familiares que habitan y producen dicha tierra cuenten con la posibilidad que ahora les brinda el Estado de poder regularizar la situación dominial de su inmueble en los términos de la Ley 24.374. Sin embargo para que dicho universo de sujetos pueda ser beneficiado con esta herramienta resulta apremiante que el gobierno local dicte la reglamentación adecuada a dicho fin.

Los inmuebles de dicha zona a los que nos referimos, se encuentran alcanzados por la finalidad que ha tenido en miras la Ley 27.118 de "Reparación histórica de la agricultura familiar para la construcción de una nueva ruralidad en la argentina", no obstante quizá pueda ocurrir que en alguno supuestos no estén

\footnotetext{
21 Garrós, Rosario y Morales Pizzo, Micaela "El otro campo": una experiencia de intervención en el cordón frutiflorihortícola del Gran La Plata. Trabajo presentado en X Jornadas de la Carrea de Trabajo Social de la Universidad de Buenos Aires (Buenos Aires, 6 y 7 de junio de 2019). http://sedici.unlp.edu.ar/handle/10915/76129

22 No es objeto de estudio en el presente trabajo, pero cabe agregar que las situaciones en que los productores arriendan los inmuebles son asimismo precarias, en términos jurídicos. La mayoría de los arrendamientos los manejan agentes inmobiliarios de la zona, dando lugar a una importante especulación del mercado inmobiliario en la región, a costos muy elevados en la intermediación, que recaen sobre los productores-arrendatarios. Dichos contratos no suelen ajustarse a la Ley 13.246 de arrendamientos y aparcerías rurales, ni respetar los tiempos mínimos allí previstos, sumado a las innumerables condiciones y clausulas perjudiciales para los arrendatarios que suelen observarse.
} 
tipificados como inmuebles rurales de acuerdo a la zonificación municipal. No obstante ello, consideramos que la reglamentación local deberá considerar y hacer prevalecer la finalidad productiva familiar de dichas tierras, más allá de la calificación urbana o rural del inmueble, permitiendo que los supuestos en que familias productoras del cordón flori-frutihorticola de La Plata reúnan los recaudos de plazo en la posesión y documentación necesaria puedan acogerse a los beneficios de la regularización dominial.

Incluso, cabe agregar que en los supuestos de arrendamientos dudosos en cuanto a la legitimidad del arrendatario como titular dominial de dichas tierras, sería propicio que luego de una debida indagación al respecto, los productores tuvieran la oportunidad de evaluar la procedencia de una eventual regularización dominial que pudiera ser aplicable, de darse los recaudos previstos por la norma.

\section{Conclusiones}

El título de propiedad formal para las familias que habitan inmuebles rurales resulta de vital importancia, en tanto brinda la seguridad necesaria en la tenencia de la tierra, que permite e incentiva al agricultor a que invierta en su explotación y eleve el rendimiento de su producción. Asimismo habilita a dichos titulares el acceso a créditos, ya que podrán ofrecer sus inmuebles como garantías reales en entidades bancarias públicas y privadas. $^{23}$

En efecto, en estudios realizados sobre asentamientos informales en la periferia de Buenos Aires, se ha detectado que las familias que contaban con títulos incrementaron sustancialmente su inversión en vivienda, redujeron su tamaño o cantidad de miembros, aumentaron la educación de sus niños, mejoraron algunos indicadores de salud (peso por altura de los niños) y redujeron las tasas de embarazo adolescente. Asimismo

\footnotetext{
23 En este caso el beneficio real y concreto sólo podrá verse en el marco de políticas públicas que también acompañen y fomenten líneas de crédito para este sector de la población.
} 
consideran que el otorgamiento de títulos puede ser una herramienta importante para la reducción de la pobreza a través del desarrollo de la inversión en capital físico y humano. ${ }^{24}$

Más allá de las innegables beneficios que esta ley trae para los agricultores familiares en pos de obtener un título formal de sus tierras, no puede perderse de vista que esta es una herramienta paliativa de la situación con una gran inversión por parte del Estado que sustenta este saneamiento en la titulación, cuando el Estado debe asimismo promover políticas que permitan prevenir estas situaciones. Y en esta dirección, es importante puntualizar que, una vez que dichas tierras entren en el mercado formal por contar con su título de dominio, el Estado debería tomar las medidas o recaudos necesarios para informar e instruir a sus adquirentes en el modo de transmitir correctamente dichos títulos para que el inmueble no vuelva a encontrarse en situación de informalidad.

Otra realidad que tampoco puede perderse de vista y debe estar presente en la agenda de las políticas públicas en esta materia, es la de evitar que los especuladores del mercado inmobiliario se aprovechen de esta situación en la cual el Estado ha invertido y puesto sus recursos a disposición a fin de regularizar un inmueble dándole su titulo formal, y compren bajo engaño y manipulaciones estos inmuebles ahora saneados y revalorizados por tal circunstancia, ya que se desvirtuaría la finalidad de la ley. ${ }^{25}$

24 Galiani, Sebastian y Schargrodsky, Ernesto (2004): "Effects of land titling on child health". Economics \& Human Biology. Volume 2, Issue 3, December 2004, pp. 353-372. https://doi. org/10.1016/j.ehb.2004.10.003. Galiani, Sebastian y Schargrodsky, Ernesto (2010): "Property Rights for the Poor: Effects of Land Titling". Journal of Public Economics 94 (2010) 700-729. Trabajos citados en GAPEL REDCOZUB, Guillermo. Políticas de regularización dominial de tierras rurales: el plan de la provincia de Corrientes, Argentina. Revista de la Facultad de Ciencias Económicas - UNNE. Número 20, otoño 2018, ISSN 1668 - 6365. Pp. 145 - 160. DOI: http://dx.doi. org/10.30972/rfce.0203259

25 No sería la primera vez que estafadores del mercado inmobiliario, convencen a una familia que les venda su inmueble con título formal a cambio de comprar por la misma suma uno quizá más grande, pero que no cuenta con una titulación suficiente, comenzando el nuevo circulo vicioso de las negativas consecuencias que acarrea la falta de título formal. 
Lo analizado en el presente trabajo nos lleva a la conclusión que resulta imprescindible contar con una adecuada reglamentación provincial el agregado producido por la Ley nacional 27.118 en la Ley 24.374, que permita a las familias poseedoras de inmuebles destinados a la producción agrícola en términos amplios, acceder a la herramienta de la regularización dominial, resultando el cordón flori-frutihortícola platense, una de las regiones a considerar especialmente en las políticas públicas locales en la materia. Asimismo entendemos que dicha norma debería estar acompañada de medidas que eviten la reincidencia en la ausencia de titulación suficiente, a fin de que la Estado garantice soluciones a largo plazo y no nos encontremos ante enmiendas momentáneas.

\section{Bibliografía}

GAPEL REDCOZUB, Guillermo (2018). "Políticas de regularización dominial de tierras rurales: el plan de la provincia de Corrientes, Argentina" en Revista de la Facultad de Ciencias Económicas - UNNE. Número 20, otoño 2018, ISSN 1668-6365. Pp. 145-160. DOI: http://dx.doi. org/10.30972/rfce.0203259

GARRÓS, Rosario y MORALES PIZZO Micaela (2019). "El otro campo: una experiencia de intervención en el cordón frutiflorihortícola del Gran La Plata". Trabajo presentado en $X$ Jornadas de la Carrea de Trabajo Social de la Universidad de Buenos Aires (Buenos Aires, 6 y 7 de junio de 2019). http:// sedici.unlp.edu.ar/handle/10915/76129.

MUÑOZ, Lorena (2008). "Regularización dominial. A más de una década de la ley 24.374. Estado de la consolidación de dominio en la Provincia de Buenos Aires y una posible actualización del régimen" en La Ley Online, Universidad Nacional de La Plata Nro. 409. 